\title{
Effect of intra-abdominal bupivacaine instillation on postoperative colonic motility
}

\author{
G RIMBÄCK, J CASSUTO, A FAXÉN, S HÖGSTRÖM, G WALLIN, \\ AND P O TOLLESSON
}

From the Departments of General Surgery, Anaesthesiology and Radiology, Central Hospital, Mölndal, Sweden

SUMMARY Effect of intra-abdominal instillation of a local anaesthetic, bupivacaine, on postoperative colonic adynamic ileus was studied in a double blind manner in a randomised series of patients undergoing upper laparotomy. Propulsive colonic activity was studied postoperatively with radio-opaque markers and serial abdominal radiographs. Intra-abdominal instillation of bupivacaine $2 \mathrm{mg} / \mathrm{kg}$ bw significantly shortened the period of postoperative colonic inhibition $(p<0.01)$, but did not hasten colonic transit. Furthermore, bupivacaine significantly decreased the hyperglycaemic response to surgery. It is suggested that bupivacaine inhibits the inflammatory response within the bowel wall, a response which may maintain the inhibitory spinal reflexes in the postoperative period. Blood concentrations of bupivacaine were shown to be well below toxic levels and no adverse reactions were observed.

Postoperative ileus is a well recognised phenomenon, characterised by impaired gastrointestinal motility leading to abdominal distension and temporarily abolished defecation. Several studies have shown that the inhibition of motility is more persistent in the stomach ${ }^{12}$ and colon $^{3}$ while activity in the small intestine returns to normal within a few hours after surgery. ${ }^{4}$ Despite extensive studies, the pathophysiology of postoperative ileus remains unclear, although the most widely accepted hypothesis suggests that postoperative ileus is caused by the activation of inhibitory reflexes originating from receptors within the gut wall and from the visceral and parietal peritoneum. ${ }^{6}$ Two types of reflexes originating within the intestine have been identified; a low threshold spinal reflex and a high threshold peripheral reflex through prevertebral ganglia. ${ }^{6}$ The efferent pathway is sympathetic ${ }^{7}$ while the nature of the afferent pathways remains obscure. Diverse treatments aimed at preventing the postoperative inhibition have been described. ${ }^{6}$ Blockade of the efferent pathway of the inhibitory reflexes by $\alpha$ - and $\beta$-adrenergic blocking agents has yielded contradictory results. ${ }^{711}$ Spinal and epidural anaesthesia

Address for correspondence: Dr A Faxén, Department of Surgery, and J Cassuto, Department of Anaesthesiology, Central Hospital, S-431 80 Mölndal, Sweden.

Received for publication 26 April 1985 have been reported to decrease postoperative bowel inhibition. ${ }^{12-14}$ None of these studies was conclusive, however, as very crude methods for registration of bowel motility were used and furthermore spinal and epidural anaesthesia do not interrupt the inhibitory prevertebral intestinal reflexes described above.

Several authors have shown an excitatory effect of local anaesthetics on intestinal smooth muscle both in vitro ${ }^{15} 16$ and in vivo, ${ }^{17}$ suggesting that these agents act by blocking inhibitory reflexes within the intestinal wall. Based on these observations, the present study was done in order to evaluate the effect of intra-abdominal instillation of a local anaesthetic on postoperative colonic inhibition, measured by the transit of radio-opaque markers.

\section{Methods}

PATIENTS

In a randomised, double blind study, 22 patients (15 women, seven men) undergoing cholecystectomy or gastric operation were investigated. The mean age and the duration of surgery did not differ significantly between the two groups of patients. Each patient gave informed consent for inclusion in the study and the experimental protocol was approved by the ethics committee at Sahlgrenska University 
Hospital, Göteborg, and by the National Board of Health.

\section{ANAESTHETIC PROCEDURES}

All subjects fasted for at least 12 hours before the operation. Pre-anaesthetic medication consisted of $0.05-0.075 \mathrm{mg}$ fentanyl and $2 \cdot 50-3.75 \mathrm{mg}$ droperidol intramusculary (Leptanal comp, Leo-Janssen, Sweden). Anaesthesia was induced with sodium thiopental $(4 \mathrm{mg} / \mathrm{kg})$. After the administration of 1 $\mathrm{mg}$ pancuronium to prevent fasciculations, endotracheal intubation was done under suxamethonium chloride relaxation $(1 \mathrm{mg} / \mathrm{kg})$. After intubation $3 \mathrm{mg}$ of pancuronium was given with additional doses of 2 $\mathrm{mg}$ as indicated during surgery. Anaesthesia was maintained with $\mathrm{N}_{2} \mathrm{O}$ and $\mathrm{O}_{2}$ and a standardised dose of $0.003 \mathrm{mg} / \mathrm{kg} / \mathrm{h}$ of fentanyl. At the conclusion of surgery $0.5 \mathrm{mg}$ atropine followed by $1 \mathrm{mg}$ neostigmine were administered to reverse neuromuscular blockade. All the patients received intercostal blockade for alleviation of pain. A total of 20 $\mathrm{ml} 0.5 \%$ bupivacaine (Marcain, Astra, Sweden) was given at the level of vertebrae $\mathrm{Th}_{8}-\mathrm{Th}_{12}$. Further postoperative pain relief was achieved by intramuscular injections of $50 \mathrm{mg}$ pethidine hydrochloride (meperidine hydrochloride USP; ACO, Sweden).

\section{TEST DRUG ADMINISTRATION}

The solutions used were $0.5 \%$ bupivacaine without preservatives (Marcain, ASTRA, Sweden) and isotonic saline, prepared by ASTRA and packed in identical packs which could not be identified by the investigators. A dose corresponding to $2 \mathrm{mg} / \mathrm{kg}$ bw bupivacaine was dissolved in $300 \mathrm{ml}$ isotonic saline before administration. A right subcostal incision was made, reaching the peritoneal level. Five millilitres of $0.5 \%$ bupivacaine were infiltrated into a small area of the peritoneum and a small opening was made into the abdominal cavity through which the test solution was instilled. To ensure that the solution was distributed all over the peritoneal surface the abdomen was gently shaken for 10 minutes after which the peritoneal opening was widened and the operation proceeded as planned.

MEASUREMENT OF COLONIC PROPULSIVE MOTILITY On the night before the operation, the patients swallowed four radio-opaque markers of different shapes. The markers (weight $0 \cdot 10-0.20 \mathrm{~g}$ ) consisted of $10 \mathrm{~mm}$ of a hollow, radio-opaque polyethylene tube filled with barium sulphate powder and sealed at the ends. Transit of the markers was followed by means of plain abdominal radiographs taken immediately after the operation and then every 12 hours, starting in the morning on the first postopera- tive day, until the markers reached the rectum or until the maximum number of radiographs allowed had been taken. The radiographs were analysed by a radiologist, who was unaware to which group the patient belonged. The colon was outlined on the radiograph and was divided into four segments; segment 0 (caecum and ascending colon), segment 1 (transverse colon), segment 2 (descending colon) and segment 3 (rectosigmoid). Starting from the end of the operation, the time taken for the markers to reach a certain segment postoperatively was recorded. Colonic transit time was estimated as the time taken for the markers to reach segment 3 minus the time taken to reach segment 1 . A record was kept of postoperative medication and of the time of the first passage of flatus and faeces.

\section{BLOOD CONCENTRATIONS OF BUPIVACAINE}

All patients received intravenous infusions of Ringer's lactate in the perioperative period. In five patients not included in the motility study, $10 \mathrm{ml}$ venous blood samples were drawn into heparinised syringes from a large, freely flowing vein distant from the site of infusion. Six samples were drawn from each patient: immediately before operation and 10, 20, 40,60, and 90 minutes after the skin incision. Samples were also taken 10, 20,30,60, and 90 minutes after administration of the intercostal blockade. The samples were kept on ice until frozen at $-20^{\circ} \mathrm{C}$. The whole blood bupivacaine concentrations were determined by ASTRA, Sweden, using a standard gas chromatography technique. ${ }^{18}$

\section{BLOOD GLUCOSE CONCENTRATIONS}

Venous blood samples $(5 \mathrm{ml})$ were drawn into heparinised syringes from eight bupivacaine treated and 11 control patients. The samples were taken immediately before operation and 30 minutes, one hour, four hours and eight hours after the skin incision. The samples were analysed using a routine glucose oxidase method.

\section{STATISTICAL METHOD}

The Wilcoxon's rank sum test was used for testing differences between the groups. Patients whose markers had not reached segment 2 and 3 were included in the statistical analysis using log-rank test for censored observations. ${ }^{19}$

\section{Results}

No side effects of the bupivacaine instillation were recorded and there was no significant difference in pethidine consumption postoperatively between the two groups of patients. 


\section{COLONIC PROPULSIVE MOTILITY}

Not all patients could be followed by means of radiographs until the markers had reached segments 2 and 3 , because the maximum number of radiographs allowed had sometimes been taken before the markers had reached these positions. This was the case in four patients in the placebo group and in one patient in the bupivacaine group. These patients are accounted for in Table 1. The prefix $>$ indicates the last time of observation of the markers in the previous segment.

In all patients but two all four markers were found in the caecum on the radiograph taken immediately after surgery. In two patients two of the markers were located in the distal ileum but were propelled into the caecum before any propagative colonic motility could be registered. The return of propulsive colonic motility postoperatively, as indicated by the propagation of radio-opaque markers from the caecum (segment 0 ) to the transverse colon (segment 1 ), was significantly faster in the bupivacainetreated patients than in controls $(\mathrm{p}<0.01$, Table 2$)$. This difference in time, amounting to about 24 hours, remained significant and constant until the markers reached the rectum (segment 3 ).

In the calculations of colonic transit time, only those patients in whom the markers could be followed to the rectum have been included. The median colonic transit time amounted to about 24 hours (bupivacaine: 25 (8-61), control 24 (16-36); median and range) and did not differ significantly between the groups.

The median time and range for the first passage of flatus and faeces postoperatively are shown in Table 2. There was no significant difference between the two groups of patients $(p>0 \cdot 10)$.

\section{BUPIVACAINE CONCENTRATION}

Figure 1 illustrates the blood concentration of bupivacaine during operation and after the intercostal blockade. The mean blood concentration reached a peak of $0.29 \mu \mathrm{g} / \mathrm{ml} 60$ minutes after the

Table 1 Time (hours) taken for the markers to reach a certain segment in five patients who could not be followed until transit of the markers was complete

\begin{tabular}{lrrrl}
\hline & \multicolumn{3}{l}{ Colonic segment } & \\
\cline { 2 - 4 } $\begin{array}{l}\text { Type of } \\
\text { operation }\end{array}$ & \multicolumn{1}{c}{1} & 2 & 3 & \\
\hline Billroth II & 91 & 103 & $>115$ & Test drug \\
Fundoplication & 106 & $>106$ & $>106$ & Saline \\
Cholecystectomy & 43 & $>130$ & $>130$ & Saline \\
Cholecystectomy & 100 & 112 & $>136$ & Saline \\
Cholecystectomy & .58 & 106 & $>106$ & Bupivacaine \\
\hline
\end{tabular}

Table 2 Time taken for the markers to reach separate segments of the colon and time elapsing before the first passage of flatus and faeces

\begin{tabular}{lcllllll}
\hline & \multicolumn{2}{l}{ Saline $(n=11)$} & & \multicolumn{2}{l}{ Bupivacaine $(n=11)$} & \\
\cline { 2 - 3 } Segment & Median & Range & & & Median & Range & p value \\
\hline 1 & 72 & $43-106$ & 48 & $33-67$ & $<0.01$ \\
2 & 91 & $77->130$ & 63 & $40-106$ & $<0.01$ \\
3 & 106 & $88->136$ & & 78 & $44->106$ & $<0 \cdot 01$ \\
Flatus & 45 & $23-61$ & & 34 & $8-54$ & $>0 \cdot 10$ \\
Faeces & 91 & $50-192$ & 73 & $26-101$ & $>0 \cdot 10$ \\
\hline
\end{tabular}

instillation of bupivacaine and slowly declined towards the end of the operation. A new peak mean concentration of $0.33 \mu \mathrm{g} / \mathrm{ml}$ was obtained 60 minutes after the intercostal blockade. Ninety minutes after the intercostal blockade the bupivacaine concentration had decreased to $0.063 \mu \mathrm{g} / \mathrm{ml}$. Blood concentrations of bupivacaine were well below toxic concentrations $(2 \cdot 0 \mu \mathrm{g} / \mathrm{ml}){ }^{20}$

\section{BLOOD GLUCOSE}

Significantly lower blood glucose concentrations were observed in the bupivacaine-treated group 30 minutes, one hour and four hours after the instillation of the local anaesthetic $(p<0.05 ;$ Fig. 2). Eight hours postoperatively, there was no significant difference in blood glucose concentrations between the two groups of patients.

\section{Discussion}

The first passage of gas and faeces has generally been used in clinical practice to indicate the return of propagative colonic motility in the postoperative period. In a recent study conducted on cholecystectomised patients we failed to show any significant correlation between the time of first passage of gas

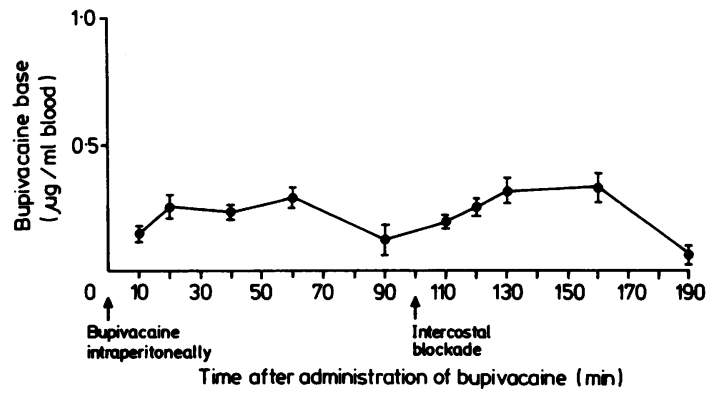

Fig. 1 Venous blood concentrations of bupivacaine in five patients after intraperitoneal instillation and after intercostal blockade. 


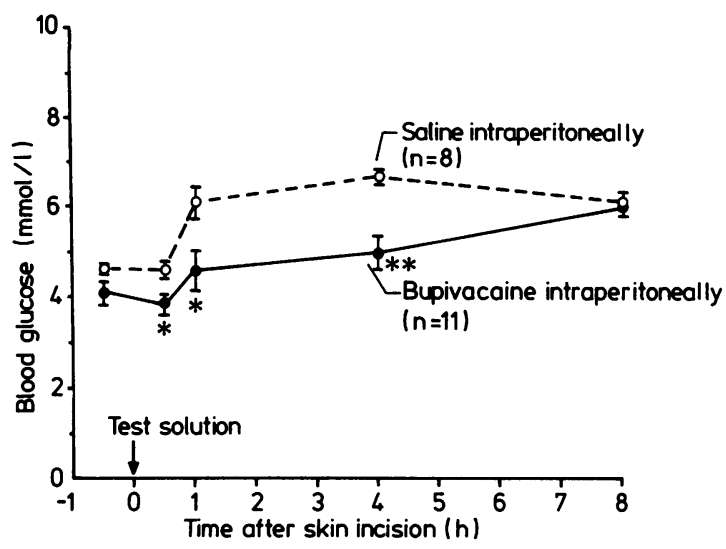

Fig. 2 Blood glucose concentrations during and after surgery in the two groups of patients. ${ }^{*} p<0.05,{ }^{* *} p<0.01$ compared with control data. Data are expressed as mean $\pm S E M$.

and the transit of radio-opaque markers in the colon in the postoperative period. ${ }^{21}$ Furthermore, there were great variations in the time of first passage of faeces, which probably reflected individual defecation habits. Also in this study great variations in the time of first passage of faeces were seen and no significant difference between the two groups could be shown despite a shorter median latency in the bupivacaine treated patients. Because the use of radio-opaque markers and serial abdominal radiographs is a more objective method, this was chosen to visualise the return of colonic propulsion in this study.

In all patients included in the study, gases were passed considerably earlier than any propulsive motility could be registered postoperatively $(p<0.01)$. Thus the results show that the first passage of flatus may be an indication of the return of some contractile activity in the colon but seems not to indicate a return of propulsive motility. These findings are in accordance with previous observations by Wilson. ${ }^{22}$

There was no significant difference in colonic transit time between the two groups of patients showing that although bupivacaine induced a faster return of colonic propulsion it did not hasten colonic transit.

Intraperitoneal lavage with bupivacaine significantly shortened the period of colonic motor inhibition after upper abdominal surgery $(\mathrm{p}<0.01$; Table 2 ). The action of bupivacaine on colonic motility could be blockade of the afferent and/or efferent link of the sympathetic inhibitory spinal nerve reflexes suggested to be involved in the pathophy- siology of adynamic postoperative ileus. ${ }^{6}$ In order to study the effect of the bupivacaine instillation on these reflexes, the blood glucose concentrations were followed during and after surgery. The hyperglycaemic response to operation is triggered by neural impulses from the site of surgery travelling to the central nervous system via afferent nerve fibres. The efferent link is mediated directly by sympathetic activity on the liver and indirectly by the release of catecholamines from the adrenal glands. ${ }^{23}$ Therefore if the stimulation of postoperative colonic motility in this study was due to inhibition of spinal nervous pathways, a concomitant inhibition of the hyperglycaemic response would be expected. We found a significant inhibition of the hyperglycaemic response during and up to eight hours after surgery in the bupivacaine treated patients, suggesting that the drug does inhibit the inhibitory spinal reflexes to the gut. The inhibition of spinal reflexes triggering the hyperglycaemic response to surgery, however, lasted for a rather short period of time (Fig. 2). During this time no colonic propulsive motility was recorded (Table 2). This suggests that the bupivacaine blockade of the intra-abdominal afferent or efferent neurones is of minor or no importance for the mechanisms underlying the effect of the drug on postoperative colonic motility.

Other possible explanations for the effect of bupivacaine on colonic motility could be blockade of inhibitory enteric neurones and/or a direct action on the intestinal smooth muscle. The circular muscle layer in the bowel has its own inherent myogenic activity and this activity is inhibited by a continuous, spontaneous discharge of action potentials within the myenteric plexus. ${ }^{24} 25$ Local anaesthetics produce an increase in electrical and mechanical activity in the intestine, as shown by Wood and Marsch. ${ }^{15}$ The excitatory effect of local anaesthetics was proposed to be secondary to blockade of inhibitory reflexes within the myenteric plexus, thereby releasing the muscle from inhibition.

In five patients not included in the motility studies in this series, bupivacaine $(2 \mathrm{mg} / \mathrm{kg}$ bw) was instilled intraperitoneally in order to measure the concentrations of bupivacaine in the blood. In these patients, a pronounced increase in gastric and intestinal motility was observed within a few minutes after the instillation of the local anaesthetic, thus supporting previous observations. ${ }^{26}$ These effects of bupivacaine should have faded away by the time propulsive motility could be recorded in our patients, however, suggesting that the initiation of colonic motility later on in the postoperative period is not an effect of bupivacaine on myenteric neurones or due to a direct effect on intestinal smooth muscle.

There is general agreement that postoperative 
adynamic ileus is caused by the activation of nerve reflexes. ${ }^{6}$ In view of the fact that even a short lasting operation in the abdominal cavity may paralyse the gut for a period of several days, ${ }^{4}$ an intra-abdominal process which maintains these reflexes must take place. In an ultrastructural study by Janik et al, ${ }^{27}$ extensive damage to the serosal surface of the intestine was observed after abdominal operations. These authors suggested that the damaged surface may act as foreign bodies and trigger an inflammatory response in the external layers of the intestinal wall. Histamine, serotonin, and kinins are known to be released in connection with the inflammatory response. ${ }^{28}$ All these agents are known to activate free nerve endings of afferent fibres. ${ }^{29}$ It was shown in a recent study that damage to the intestinal serosa by several noxious agents caused an inflammatory reaction, leading to the activation of intrinsic nervous reflexes which could be biocked with local anaesthetics applied to the serosal surface. ${ }^{30}$ There is thus good evidence that the inflammatory reaction in the serosa - for example, after mechanical manipulation - may activate spinal and/or intrinsic nerve reflexes.

Local anaesthetics are known to have several properties in common with anti-inflammatory and antihistaminic drugs as virtually all of these compounds are surface active ${ }^{31-33}$ This property of local anaesthetics was recently confirmed in a study showing that intravenous infusion of lidocaine caused almost complete inhibition of the inflammatory response to aseptic peritonitis in the rabbit. ${ }^{34}$

It is concluded that intra-abdominal instillation of bupivacaine shortens the period of postoperative colonic inhibition. The long term effect of bupivacaine on colonic motility in our study could be because of inhibition of the release of nerve active inflammatory agents, thus preventing the initiation and maintenance of inhibitory intestinal reflexes.

This work was supported by the Medical Society of Göteborg, Göteborgs and Bohus Läns Landsting and by the ASTRA Research Foundation. The authors are grateful to $\mathrm{Dr} H$ Evers, Medical Department, ASTRA Läkemedel, Södertälje, for his help and advice.

\section{References}

1 Rothnie NG, Harper RA, Catchpole BN. Early postoperative gastrointestinal activity. Lancet 1963; 2: 64-7.

2 Nachlas M, Younis MT, Roda Claro Pio, Wityk JJ. Gastrointestinal motility as a guide to postoperative management. Ann Surg 1972; 175: 510-22.
3 Woods JH, Erickson LW, Condon RE, Schulte WJ, Sillin JF. Postoperative ileus: a colonic problem? Surgery 1978; 84: 527-33.

4 Graber JN, Schulte WJ. Relationship of duration of postoperative ileus to extent and site of operative dissection. Surgery 1982; 92: 87-92.

5 Tinckler LF. Surgery and intestinal motility. Br J Surg $1965 ;$ 42: 140-50.

6 Furness JB, Costa M. Adynamic ileus, its pathogenesis and treatment. Med Biol 1974; 52: 82-9.

7 Neely J, Catchpole B. Ileus: the restoration of alimentary tract motility by pharmacological means. BrJ Surg 1971; 58: 21-8.

8 Petri G, Szenohradszhy J, Porszasz-Gibiszer K. Sympatholytic treatment of 'paralytic' ileus. Surgery 1971; 70: 359-67.

9 Kinnaert P, Panda M, Denvaert F. Use of chlorpromazine in the treatment of adynamic ileus. World J Surg 1977; 1: 655-60.

10 Heimbach DM, Crout JR. Treatment of paralytic ileus with adrenergic neuronal blocking drugs. Surgery 1971; 69: $582-7$.

11 Smith J, Kelly KA, Weinshilboum KM. Pathophysiology of postoperative ileus. Arch Surg 1977; 112: 203-9.

12 Markowitz J, Campbell WR. The relief of experimental ileus by spinal anesthesia. Am J Physiol 1927; 81: 101-6.

13 Acalovschi I, Badea G. Efficiency of continued (intermittent) peridural anesthesia in the prevention of postoperative ileus. Rev Chir 1978; 27: 315-8.

14 Fasano M, Waldvogel HH, Muller CA. Prophylaxie de l'iléus paralytique apres chirurgie du colon par blocage sympatique péridural continu. Helv Chir Acta 1979; 46: 245-8.

15 Wood JD, Marsch DR. Effects of atropine, tetrodotoxin and lidocaine on rebound excitation of guineapig small intestine. J Pharmacol Exp Ther 1973; 184: $590-8$.

16 Bortoff A, Muller R. Stimulation of intestinal smooth muscle by atropine, procaine and tetrodotoxin. $A m \mathrm{~J}$ Physiol 1975; 229: 1609-13.

17 Biber B, Fara J. Intestinal motility increased by tetradotoxin, lidocaine and procaine. Experientia 1973; 29: $551-2$.

18 Mather LE, Tucker GT. Meperidine and other basic drugs: general method for their determination in plasma. J Pharm Sci 1974; 63: 306-7.

19 Cox DR, Oakes D. Analysis of survival data. London: Chapman-Hall, 1984: 104.

20 Moore DC, Mather LE, Bridenbaugh LD, et al. Bupivacaine (marcaine): an evaluation of its tissue and systemic toxicity in humans. Acta Anesthesiol Scand 1977; 21: 109-12.

21 Tollesson PO, Cassuto J, Faxén, A, Rimbäck G, Wallin G. Is the first passage of flatus and faeces a valid indicator of the return of propulsive colonic motility in the postoperative period? [Abstract]. Gut 1984; 25: A1313-4.

22 Wilson JP. Postoperative motility of the large intestine in man. Gut 1975; 16: 689-92.

23 Bromage PR, Shibata HR, Willoughby HW. Influence of prolonged epidural blockade on blood sugar and 
cortisol responses to operations upon the upper part of the abdomen and the thorax. Surg Gynecol Obstet 1971; 132: 1051-6.

24 Wood JD. Electrical activity from single neurons in Auerbach's plexus. Am J Physiol 1970; 219: 159-69.

25 Ohkawa H. Prosser CL. Comparison of myenteric and submucous neurons in small intestine. Fed Proc 1971; 30: 436 .

26 Thompson GE. Celiac plexus, intercostal and minor peripheral blockade. In: Cousins JC, Bridenbugh PO, eds. Neural blockade in clinical anesthesia and management of pain. New York: Lippincott, 1980: 384-404.

27 Janik JS, Apkarian R, Nagaraj HS, Groff DB. An ultrastructural study of enteric serosa after surgical management. Surg Gynecol Obstet 1982; 152: 491-6.

28 DiRosa M, Giroud JP, Willoughby DA. Studies of the mediators of the acute inflammatory response induced in rats in different sites by carrangeenan and turpentine. J Pathol 1971; 104: 15-29.

29 Chahl LA. Pain induced by inflammatory mediators.
In: Beers Jr RF, Basset EG, eds. Mechanisms of pain and analgesic compounds. New York: Raven Press, 1979: 273-84.

30 Brunsson I, Sjöqvist I, Jodal M, Lundgren O. Mechanisms underlying the intestinal fluid secretion evoked by nociceptive serosal stimulation of the rat. $N S$ Arch Pharmacol 1985; 328: 439-45.

31 Tanaka K, Iizuka Y. Suppresion of enzyme release from isolated rat liver lysosomes by non-steroidal anti-inflammatory drugs. Biochem Pharmacol 1968; 17: 2023-32.

32 Seeman P. The membrane actions of anesthetics and tranquilizers. Pharmacol Rev 1972; 24: 583-655.

33 Goodman LS, Gilman A (eds.) The pharmacological basis of therapeutics. New York: MacMillan, 1975: 325-58.

34 MacGregor RR, Thorner RE, Wright DM. Lidocaine inhibits granulocyte adherence and prevents granulocyte delivery to inflammatory sites. Blood 1980; 56: 203-9. 